\title{
Maintenance of the Results of Stage II Lower Limb Lymphedema Treatment after Normalization of Leg Size
}

\author{
Jose Maria Pereira de Godoy, ${ }^{1}$ Henrique Jose Pereira de Godoy, ${ }^{2,3}$ Renata Lopes Pinto, \\ Fernando Nestor Facio Jr., ${ }^{5}$ and Maria de Fatima Guerreiro Godoy ${ }^{4}$ \\ ${ }^{1}$ Cardiology and Cardiovascular Surgery Department, Faculty of Medicine of São José do Rio Preto (FAMERP), \\ National Council for Research and Development (CNPq), São José do Rio Preto, SP, Brazil \\ ${ }^{2}$ Universidade Federal do Mato Grosso, Cuiabá, MT, Brazil \\ ${ }^{3}$ Research Group of Clínica Godoy, São José do Rio Preto, SP, Brazil \\ ${ }^{4}$ Faculty of Medicine of São José do Rio Preto (FAMERP) and Research Group of Clínica Godoy, São José do Rio Preto, SP, Brazil \\ ${ }^{5}$ Faculty of Medicine of São José do Rio Preto (FAMERP), São José do Rio Preto, SP, Brazil
}

Correspondence should be addressed to Jose Maria Pereira de Godoy; godoyjmp@gmail.com

Received 10 April 2017; Accepted 20 June 2017; Published 1 August 2017

Academic Editor: Robert M. Schainfeld

Copyright ( 2017 Jose Maria Pereira de Godoy et al. This is an open access article distributed under the Creative Commons Attribution License, which permits unrestricted use, distribution, and reproduction in any medium, provided the original work is properly cited.

\begin{abstract}
Objective. The aim of this study was to identify strategies to transfer responsibility of the maintenance of the results of lymphedema treatment to the patient. Methods. Maintenance of the reduction of edema was evaluated in a prospective clinical trial in patients with Stage II leg lymphedema. Twenty-one lymphedematous lower limbs were evaluated in Clínica Godoy in 2014 and 2016 . The evaluation was done by volumetry at baseline and weekly thereafter for volume control. Patients wore Venosan ${ }^{\circledR} \operatorname{cotton} 20 / 30$ and $30 / 40 \mathrm{mmHg}$ elastic compression stockings followed by a custom-made inelastic stocking made of grosgrain fabric. The Friedman test for multiple comparisons and Conover post hoc test were used for statistical analysis with an alpha error of $5 \%$. Results. On comparing leg volume changes using the different types of stockings, the $20 / 30 \mathrm{mmHg}$ elastic compression stockings failed in the first week to maintain the volume reductions but the $30 / 40 \mathrm{mmHg}$ compression stockings did not allow significant increases in volume ( $p$ value $>0.05)$. During one week, the grosgrain stocking reduced leg volumes to baseline values $(p$ value $=0.24)$. Conclusion. Higher compression of elastic stockings is better than lower compression but the inelastic grosgrain stocking is even better than both to maintain the results.
\end{abstract}

\section{Introduction}

Lymphedema is a chronic medical condition resulting from the accumulation of macromolecules in the interstitial space that leads to fluid retention. This condition may be due to congenital or acquired dysfunction of the lymphatic system [1].

Manual and Mechanical (RAGodoy ${ }^{\circledR}$ ) Lymphatic Therapy cause the mobilization of macromolecules with reductions of the edema while compression mechanisms are key to maintaining the results [2]. The reduction of limb volume occurs due to loss of liquid by diuresis and redistribution of macromolecules and body fluid [3]. Thus, the association of drainage with restraint mechanisms, such as stockings or bandaging, can have a synergistic effect in reducing edema $[4,5]$.

Compression mechanisms can be elastic or inelastic; because of the differences in pressure at the skin-stocking interface, these characteristics affect treatment outcome [6]. Stockings have a great advantage because of their practicality; they can be donned and removed by the patient [5]. Bandages, on the other hand, require a specialized professional, as rarely patients are able to apply bandages by themselves [7-9].

Maintaining the results of lymphedema treatment is a challenge that requires continuous maintenance and frequent evaluations. Because of the chronicity of the disease, flexibility in the therapy and passing part of the responsibility of treatment to the patient are important to increase 
TABLE 1: Volumes of legs using 20/30 and 30/40 mmHg elastic and low-stretch compression stockings.

\begin{tabular}{|c|c|c|c|c|c|c|c|c|c|}
\hline \multirow{3}{*}{ Baseline } & \multicolumn{4}{|c|}{ 20/30 mmHg compression stocking } & & \multicolumn{4}{|c|}{$30 / 40 \mathrm{mmHg}$ compression stocking } \\
\hline & \multicolumn{4}{|c|}{ Week } & \multirow[t]{2}{*}{ Grosgrain } & \multicolumn{4}{|c|}{ Week } \\
\hline & 1st & 2nd & 3rd & 4 th & & 1st & 2nd & 3rd & 4 th \\
\hline 4046 & 4047 & 3957 & 3912 & 3949 & 3839 & 3879 & 3721 & 3890 & 3804 \\
\hline 2601 & 2637 & 2590 & 2679 & 2643 & 2625 & 2671 & 2640 & 2670 & 2611 \\
\hline 2993 & 3068 & 3041 & 3050 & 3043 & 2928 & 2989 & 2946 & 2932 & 2906 \\
\hline 2775 & 2727 & 2775 & 2666 & 2676 & 2616 & 2622 & 2819 & 2729 & 2657 \\
\hline 2998 & 3080 & 3132 & 3011 & 3087 & 3081 & 3107 & 2926 & 3103 & 2991 \\
\hline 3434 & 3360 & 3468 & 3451 & 3453 & 3315 & 3399 & 3491 & 3370 & 3441 \\
\hline 3152 & 3373 & 3351 & 3282 & 3289 & 3268 & 3186 & 3211 & 3277 & 3178 \\
\hline 2971 & 3107 & 3363 & 3202 & 3369 & 2995 & 3098 & 2949 & 2975 & 3057 \\
\hline 2996 & 3236 & 3254 & 3270 & 3263 & 2819 & 3112 & 3164 & 3106 & 3264 \\
\hline 2811 & 3206 & 3348 & 3493 & 3489 & 2628 & 3149 & 3141 & 3368 & 3381 \\
\hline 3672 & 3815 & 3895 & 3772 & 3944 & 3805 & 3787 & 3709 & 3892 & 3786 \\
\hline 3748 & 3838 & 3782 & 3725 & 3685 & 3669 & 3692 & 3588 & 3588 & 3542 \\
\hline 3103 & 3073 & 3015 & 3105 & 3122 & 3034 & 2865 & 3012 & 3045 & 3063 \\
\hline 2640 & 2701 & 2730 & 2783 & 2755 & 2577 & 2669 & 2557 & 2662 & 2726 \\
\hline 2935 & 3197 & 3279 & 3158 & 3238 & 3115 & 3270 & 2943 & 3222 & 3050 \\
\hline 3305 & 3451 & 3286 & 3325 & 3374 & 3316 & 3367 & 3354 & 3204 & 3393 \\
\hline 3261 & 3573 & 3519 & 3444 & 3380 & 3206 & 3322 & 3329 & 3312 & 3346 \\
\hline 3114 & 3065 & 3318 & 3208 & 3292 & 3055 & 3055 & 3084 & 3123 & 3176 \\
\hline 2999 & 3137 & 3069 & 3047 & 3117 & 2913 & 3158 & 3069 & 2952 & 3060 \\
\hline 2793 & 2870 & 3086 & 3146 & 3018 & 2673 & 2975 & 3056 & 3122 & 3032 \\
\hline 3915 & 4147 & 4328 & 4013 & 4159 & 3964 & 3994 & 3882 & 4054 & 4075 \\
\hline
\end{tabular}

independence. The improvement in the quality of life of these patients including the physical, mental, and social domains is important and thus, stockings and constraint mechanisms can improve compliance and help maintain treatment results [10].

In recent years, Godoy \& Godoy identified a type of textile named gorgurão in Brazil and grosgrain in English that satisfies the basic requisites for a compression garment that can be used to treat lymphedema. This fabric has different weights per square meter and thus adaptations need to be made depending on the quality of fabric used; however several studies show that it is suitable to treat lymphedema [11-13]. A soon-to-be-published study shows that it is even effective as monotherapy to reduce leg volume in patients with Stage II lymphedema.

The aim of this study was to identify strategies to maintain the results after total reduction of edema so that some of the responsibility of lymphedema treatment can be transferred to the patient.

\section{Method}

Twenty-one legs of 14 female and three male patients with lymphedema were evaluated in Clínica Godoy between 2013 and 2014. The mean age of the participants was 59.4 years.

Patients with Stage II lymphedema of the lower limbs, regardless of cause, were included if the size of the leg after treatment was within the normal range compared to the contralateral leg. Elderly patients were excluded, as were patients with chronic arterial insufficiency, morbid obesity, infections, joint immobility, or any other condition that would prevent the use of stockings. Patients were consecutively enrolled in order of arrival at the clinic.

The legs were evaluated by volumetry using the water displacement technique at baseline and weekly thereafter to control leg volume. Initially all patients wore Venosan 20/30 $\mathrm{mmHg}$ elastic compression stockings for four weeks. Subsequently, they used an inelastic custom-made stocking of grosgrain for one week. Finally, a Venosan 30/40 mmHg compression stocking was worn for four weeks.

\section{Statistical Analysis}

Descriptive statistics such as the mean, median, standard deviation, range, and upper and lower quartiles were used in the statistical analysis. The Friedman test for multiple comparisons and Conover post hoc test were used for statistical analysis with an alpha error of 5\% being considered acceptable. This study was approved by the Research Ethics Committee of the Faculty of Medicine of São José do Rio Preto (FAMERP) number 052758/2014 (\#CAAE: 32771414.8.40.54.15).

\section{Results}

Small and large variations in volume were detected during the study in part related to the type of compression stocking employed (Table 1). Table 2 shows the descriptive 
TABLE 2: Comparison between the initial volumes after treatment and volume variations over the weeks with patients using $20 / 30$ and $30 / 40 \mathrm{mmHg}$ elastic compression stockings and a grosgrain stocking.

\begin{tabular}{|c|c|c|c|c|c|c|c|}
\hline Title & Mean & Median & Maximum & Minimum & Upper quartile & Lower quartile & Standard deviation \\
\hline Baseline & 3155.333 & 2999 & 4046 & 2601 & 3305 & 2935 & 403.4275 \\
\hline \multicolumn{8}{|c|}{ 20/30 mmHg elastic stocking } \\
\hline 1st & 3271.81 & 3197 & 4147 & 2637 & 3451 & 3068 & 419.9758 \\
\hline 2nd & 3313.619 & 3286 & 4328 & 2590 & 3468 & 3069 & 420.6742 \\
\hline $3 r d$ & 3273.429 & 3208 & 4013 & 2666 & 3451 & 3050 & 368.7153 \\
\hline 4th & 3302.143 & 3289 & 4159 & 2643 & 3453 & 3087 & 398.5773 \\
\hline Grosgrain & 3116.238 & 3055 & 3964 & 2577 & 3315 & 2819 & 420.7277 \\
\hline \multicolumn{8}{|c|}{ 30/40 mmHg elastic stocking } \\
\hline 1st & 3207.905 & 3149 & 3994 & 2622 & 3367 & 2989 & 382.0806 \\
\hline 2nd & 3171.00 & 3084 & 3882 & 2557 & 3354 & 2946 & 352.563 \\
\hline $3 \mathrm{rd}$ & 3218.857 & 3123 & 4054 & 2662 & 3368 & 2975 & 383.0062 \\
\hline 4th & 3216.143 & 3176 & 4075 & 2611 & 3393 & 3032 & 377.2265 \\
\hline
\end{tabular}

TABLE 3: Multiple comparisons between weekly volume changes of the legs wearing different stockings.

\begin{tabular}{lc}
\hline Comparison & $p$ value \\
\hline Baseline versus 1st week 20/30 stocking & $<0.0001$ \\
Baseline versus 2nd week 20/30 stocking & $<0.0001$ \\
Baseline versus 3rd week 20/30 stocking & $<0.0001$ \\
Baseline versus 4th week 20/30 stocking & $<0.0001$ \\
\hline Baseline versus 1st week 30/40 stocking & 0.08 \\
Baseline versus 2nd week 30/40 stocking & 0.73 \\
Baseline versus 3rd week 30/40 stocking & 0.08 \\
Baseline versus 4th week 30/40 stocking & 0.15 \\
\hline 1st week 20/30 versus 1st week 30/40 stocking & 0.01 \\
2nd week 20/30 versus 2nd week 30/40 stocking & 0.001 \\
3rd week 20/30 versus 3rd week 30/40 stocking & 0.01 \\
4th week 20/30 versus 4th week 30/40 stocking & 0.0002 \\
\hline Baseline versus 1st week grosgrain stocking & 0.24 \\
\hline
\end{tabular}

statistics (mean and median, standard deviation, minimum and maximum variations, and upper and lower quartiles). Table 3 shows the results of the Conover multiple comparisons test for volume changes using the Venosan 20/30 and $30 / 40 \mathrm{mmHg}$ elastic stockings and the low-stretch grosgrain stocking.

The Friedman test identified significant differences in volumes $(p$ value $<0.0001)$. When the final volumes related to the different types of stockings were compared using the Conover multiple comparisons test, the $20 / 30 \mathrm{mmHg}$ compression stockings failed to maintain volume loss with a significant increase being seen within the first week ( $p$ value $<$ 0.0001 ). However, on using $20 / 30 \mathrm{mmHg}$ compression stockings, there were no significant volume differences comparing the first week with subsequent weeks (Table 3 and Figure 1).

When the respective weeks of $20 / 30 \mathrm{mmHg}$ stockings are compared to $30 / 40 \mathrm{mmHg}$ compression stockings, the latter was better to maintain treatment results ( $p$ values $<0.05)$. Use of the grosgrain stocking for one week reduced the sizes of the limbs to the baseline values ( $p$ value $=0.24$; Figure 2 ).

\section{Discussion}

This study evaluated the strategy to maintain reductions in edema in patients submitted to treatment for lymphedema of the lower limbs using different elastic compression stockings and a low-stretch stocking made of grosgrain. Stockings with higher compression $(30 / 40 \mathrm{mmHg})$ are superior to $20 / 30 \mathrm{mmHg}$ compression stockings in the maintenance of treatment results. The $30 / 40 \mathrm{mmHg}$ stocking preserved volume reductions over four weeks. However, the low-stretch stocking (grosgrain) is better than both elastic stockings in maintaining treatment results and even reducing the volume.

One of the challenges in the treatment of lymphedema is the maintenance of the results after total reduction of edema. It is known that lymphedema has no cure, so long-term maintenance therapy is critical throughout the lifetime of patients. The identification of alternative flexible approaches that improve patient compliance is important for therapeutic success. Recently, total reduction in the volume of edema ceased to be a major challenge in the treatment of these patients and consequently the maintenance of volume losses now requires more attention.

Elastic stockings, due to their convenience and availability, are a very good option to maintain volume reductions. However, they do not always preserve treatment results, perhaps due to a series of failures in the indication of an appropriate stocking.

Another aspect that draws attention in the clinical practice is about the use of stockings during the edema reduction phase. Manual and mechanical lymph drainage allow a rapid reduction of edema volume and the use of an elastic stocking has a synergistic effect in reducing edema during drainage. Therefore, the association of drainage with elastic stockings or bandages is essential at this stage. However, when reductions in limb size are more than 200 to $300 \mathrm{~mL}$, the stockings fail to maintain further losses. In this phase, two stockings can be used, one on top of the other, or the stocking should be replaced.

Total reduction of edema is the goal of therapy; this should be achieved as soon as possible because it facilitates access of the patient to standard-sized stockings. Bandages 


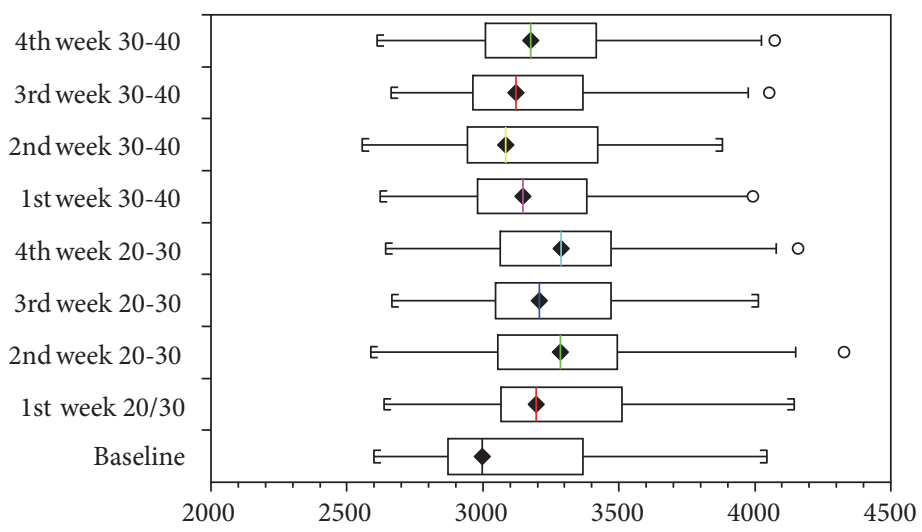

FIGURE 1: Volume changes in different weeks of treatment wearing 20/30 and 30/40 mmHg compression stockings.

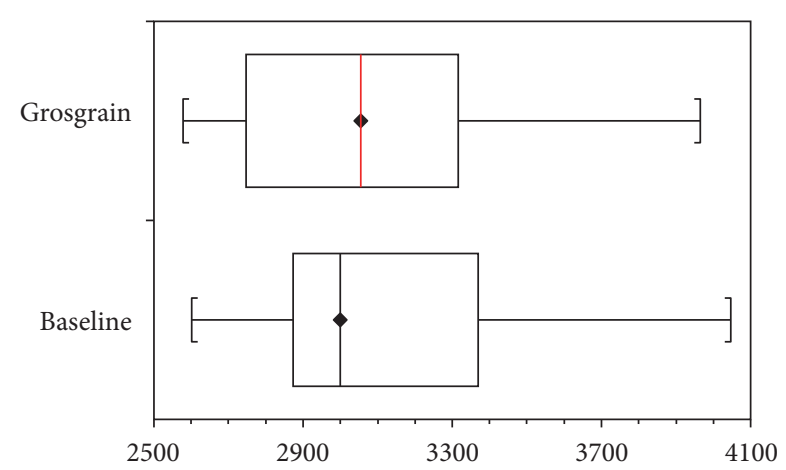

FIGURE 2: Interquartile range of volume changes between the baseline value and after one week of wearing grosgrain stockings.

can contribute to reductions in limb volume and are a further option [11].

The literature shows that stockings with high compression are the most suitable [10], but not all of the world's population has access to these stockings. Although this study shows that stockings with higher compression are better, lower compression can be used when there is no alternative.

Another important result of this study is related to grosgrain stockings, which currently are made by hand, but can be mass-produced. After total reduction of edema, patients themselves can make precise adjustments to the stocking as required. Grosgrain stockings can be used as monotherapy to normalize the size of the leg and maintain the results of lymphedema treatment. What limits their use is the time needed to don the stocking, which is about 10 minutes compared to 2 to 3 minutes for an elastic stocking. However, flexibility in using these stockings, according to need, will allow the patient to maintain normal or close to normal leg size.

In this study, the weekly volume variations were not large; the largest mean variation using elastic stockings was $158 \mathrm{~mL}$ with the $20 / 30 \mathrm{mmHg}$ compression stockings compared to $63 \mathrm{~mL}$ with $30 / 40 \mathrm{mmHg}$ compression. However, the use of a grosgrain stocking for one week reduced the leg volume by
$159 \mathrm{~mL}$ on average, that is, below the initial volume, albeit not statistically significant.

Another key aspect is that the patient is able to control treatment, similar to other chronic diseases. It is essential for the professional to identify the time that each patient should return for assessments.

This study describes strategies to transfer part of the responsibility of lymphedema treatment to patients providing conditions for them to maintain the leg size within the normal range or close to it. Thus, the combination of grosgrain stockings with manual lymph drainage, when necessary, extends the therapeutic possibilities to control swelling. After complete reduction of the edema, maintenance therapy can be continued in accordance with the conditions and needs of each patient.

\section{Conclusion}

Elastic stockings with higher compression are superior to those of lower compression; however the inelastic grosgrain stocking is better than both, decreasing volume of lymphedema and maintaining the results. However, the practicality of elastic stockings makes them a good option; alternating elastic and low-stretch grosgrain stockings allows the patient to maintain volume reductions within the normal range or close to it.

\section{Conflicts of Interest}

The authors declare that they have no conflicts of interest.

\section{References}

[1] B. B. Lee, M. Andrade, P. L. Antignani et al., "Diagnosis and treatment of primary lymphedema consensus document of the international union of phlebology (IUP)-2013," International Angiology, vol. 32, no. 6, pp. 541-574, 2013.

[2] C. E. Q. Belczak, J. M. P. de Godoy, R. N. Ramos, M. A. de Oliveira, S. Q. Belczak, and R. A. Caffaro, "Rate of occupational leg swelling is greater in the morning than in the afternoon," Phlebology, vol. 24, no. 1, pp. 21-25, 2009. 
[3] J. M. Pereira De Godoy, P. A. Franco Brigidio, S. X. Salles Cunha, F. Batigália, and M. De Fatima Guerreiro Godoy, "Mobilization of fluids in large volumetric reductions during intensive treatment of leg lymphedema," International Angiology, vol. 32, no. 5, pp. 479-482, 2013.

[4] C. E. Q. Belczak, J. M. P. de Godoy, S. Q. Belzack, M. A. D. M. Silva, and R. A. Caffaro, "Compression stockings have a synergistic effect with walking in the late afternoon to reduce edema of the lower limbs," International Angiology, vol. 31, no. 5, pp. 490-493, 2012.

[5] J. M. P. De Godoy, R. Lopes Pinto, A. C. Pereira De Godoy, and M. De Fátima Guerreiro Godoy, "Synergistic effect of adjustments of elastic stockings to maintain reduction in leg volume after mechanical lymph drainage," International Journal of Vascular Medicine, vol. 2014, Article ID 640189, 2014.

[6] J. M. P. de Godoy, D. M. Braile, F. B. Perez, and M. D. F. G. Godoy, "Effect of walking on pressure variations that occur at the interface between elastic stockings and the skin," International Wound Journal, vol. 7, no. 3, pp. 191-193, 2010.

[7] N. Stout, H. Partsch, G. Szolnoky et al., "Chronic edema of the lower extremities: international consensus recommendations for compression therapy clinical research trials," International Angiology, vol. 31, no. 4, pp. 316-329, 2012.

[8] G. Mosti, P. Picerni, and H. Partsch, "Compression stockings with moderate pressure are able to reduce chronic leg oedema," Phlebology, vol. 27, no. 6, pp. 289-296, 2012.

[9] G. Mosti and H. Partsch, "Bandages or double stockings for the initial therapy of venous oedema? A randomized, controlled pilot study," European Journal of Vascular and Endovascular Surgery, vol. 46, no. 1, pp. 142-148, 2013.

[10] E. K. Symvoulakis, D. I. Anyfantakis, and C. Lionis, "Primary lower limb lymphedema: a focus on its functional, social and emotional impact," International Journal of Medical Sciences, vol. 7, no. 6, pp. 353-357, 2010.

[11] M. F. G. Godoy, J. M. P. Godoy, and D. M. Braile, "Pilot study with Myolymphokinetic activities in the treatment of lymphedema after breast cancer," Indian Journal of Physiotherapy and Occupational Therapy, vol. 2, no. 3, pp. 17-19, 2008.

[12] J. M. P. Godoy and M. F. G. Godoy, "Assessment of inelastic sleeves in patients with upper limb lymphoedema," Indian Journal of Physiotherapy and Occupational Therapy, vol. 1, no. 4, pp. 3-5, 2007.

[13] S. Couzan, A. Leizorovicz, S. Laporte et al., "A randomized double-blind trial of upward progressive versus degressive compressive stockings in patients with moderate to severe chronic venous insufficiency," Journal of Vascular Surgery, vol. 56, no. 5, pp. 1344-1350, 2012. 


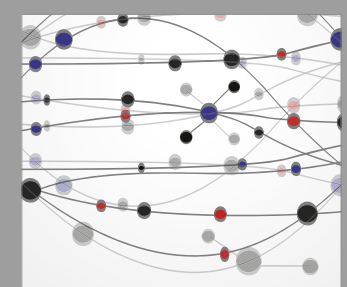

The Scientific World Journal
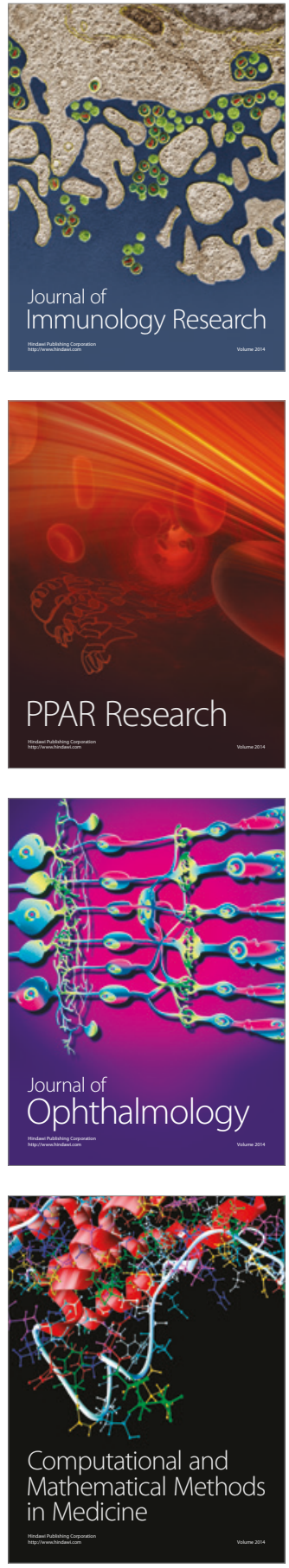

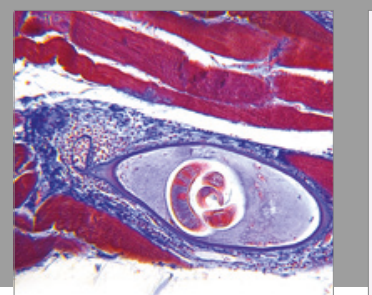

Gastroenterology Research and Practice
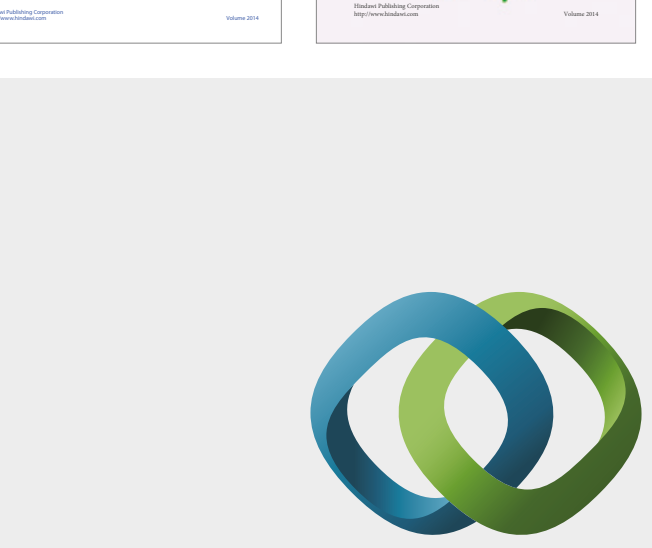

\section{Hindawi}

Submit your manuscripts at

https://www.hindawi.com
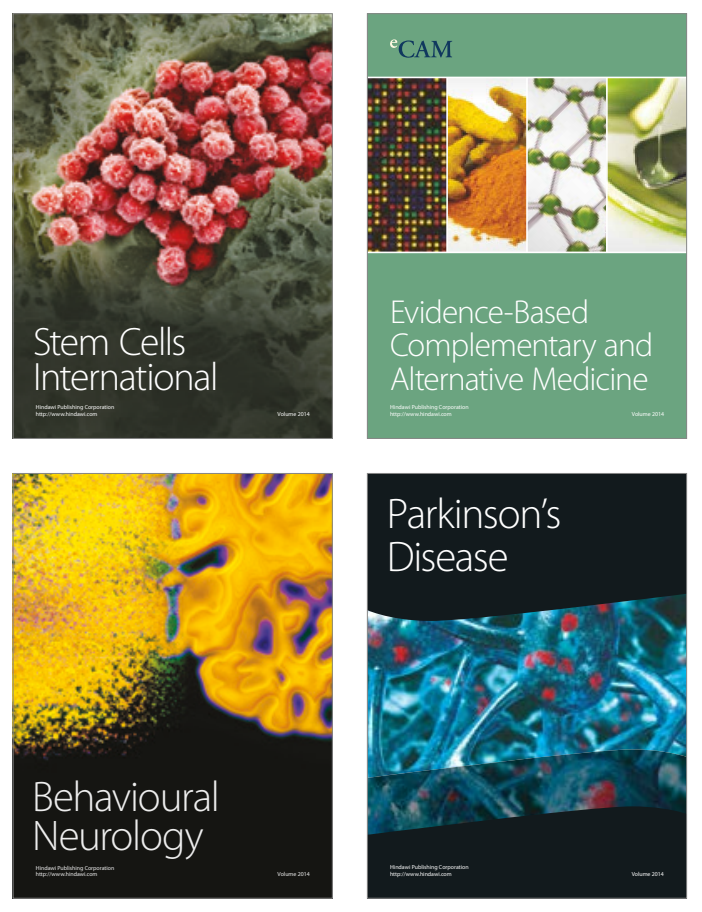
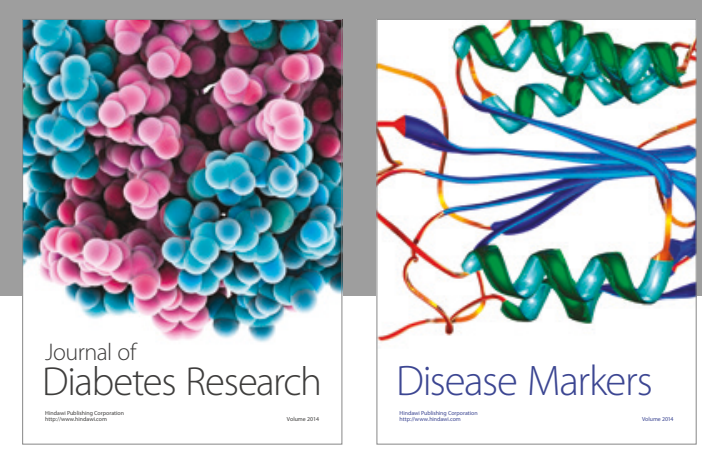

Disease Markers
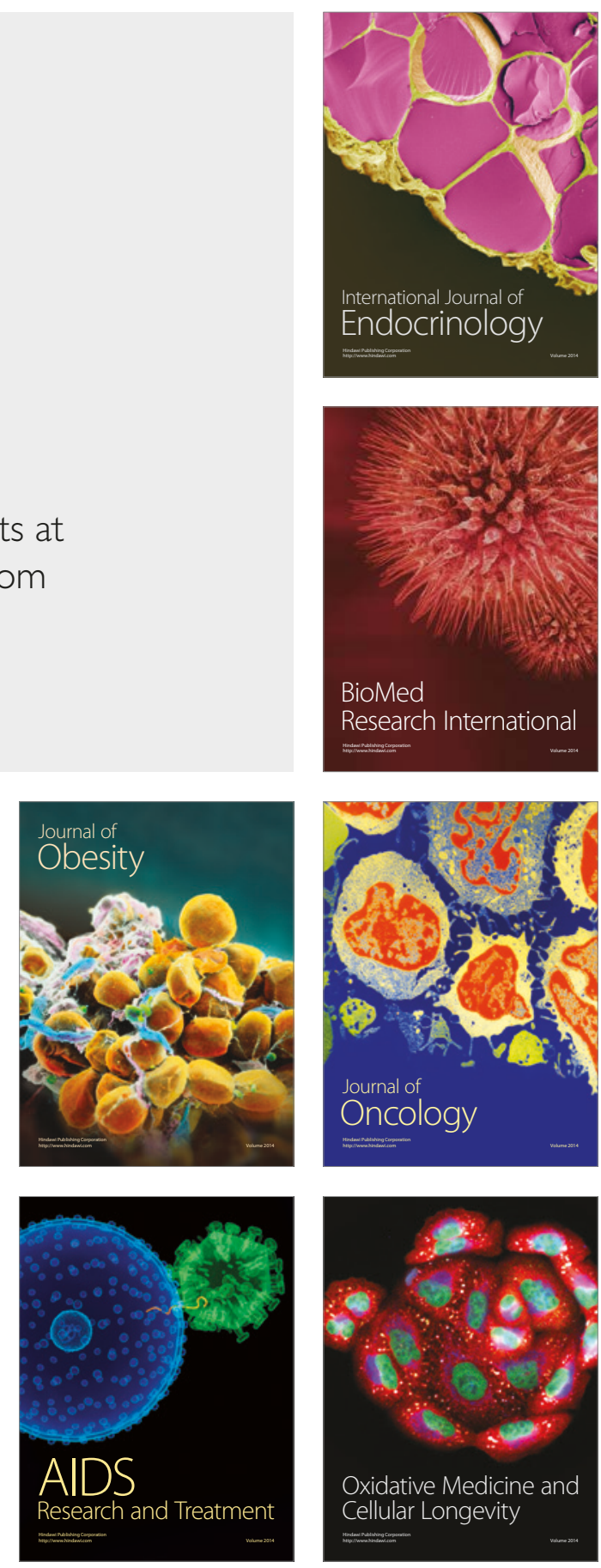